This item was submitted to Loughborough's Research Repository by the author.

Items in Figshare are protected by copyright, with all rights reserved, unless otherwise indicated.

\title{
An afternoon snack of berries reduces subsequent energy intake compared to an isoenergetic confectionary snack
}

PLEASE CITE THE PUBLISHED VERSION

http://dx.doi.org/10.1016/j.appet.2015.07.005

PUBLISHER

(C) Elsevier

VERSION

AM (Accepted Manuscript)

\section{PUBLISHER STATEMENT}

This work is made available according to the conditions of the Creative Commons Attribution-NonCommercialNoDerivatives 4.0 International (CC BY-NC-ND 4.0) licence. Full details of this licence are available at: https://creativecommons.org/licenses/by-nc-nd/4.0/

\section{LICENCE}

CC BY-NC-ND 4.0

\section{REPOSITORY RECORD}

James, Lewis J., Mark P. Funnell, and Samantha Milner. 2019. "An Afternoon Snack of Berries Reduces Subsequent Energy Intake Compared to an Isoenergetic Confectionary Snack". figshare. https://hdl.handle.net/2134/18821. 
2 An afternoon snack of berries reduces subsequent energy intake compared to an

3 isoenergetic confectionary snack

4

5 Lewis J. James ${ }^{1}$, Mark P. Funnell ${ }^{1}$ and Samantha Milner ${ }^{1}$

$6{ }^{1}$ School of Sport, Exercise and Health Sciences, Loughborough University, 7 Leicestershire, UK, LE11 3TU.

8

9 Corresponding author

10 Lewis J. James

11 L.james@lboro.ac.uk

12 School of Sport, Exercise and Health Sciences

13 Loughborough University 


\section{Abstract}

15 Observational studies suggest that increased fruit and vegetable consumption can contribute to weight maintenance and facilitate weight loss when substituted for other energy dense foods. Therefore, the purpose of the present study was to assess the effect of berries on acute appetite and energy intake. Twelve unrestrained premenopausal women (age $21 \pm 2 \mathrm{y}$; BMI $26.6 \pm 2.6 \mathrm{~kg} \cdot \mathrm{m}^{-2}$; body fat $23 \pm 3 \%$ )

20 completed a familiarisation trial and two randomised experimental trials. Subjects 21 arrived in the evening ( $\sim \mathrm{pm})$ and consumed an isoenergetic snack (65 kcal) of 22 mixed berries (BERRY) or confectionary sweets (CONF). Sixty min later, subjects consumed a homogenous pasta test meal until voluntary satiation, and energy intake was quantified. Subjective appetite (hunger, fullness, desire to eat and prospective food consumption) was assessed throughout trials, and for $120 \mathrm{~min}$ after the test meal. Energy intake was less $(P<0.001)$ after consumption of the BERRY snack $(691$

$27 \pm 146 \mathrm{kcal})$ than after the CONF snack (824 $\pm 172 \mathrm{kcal})$; whilst water consumption 28 was similar $(P=0.925)$. There were no trial $(P>0.095)$ or interaction $(P>0.351)$ effects 29 for any subjective appetite ratings. Time taken to eat the BERRY snack $(4.05 \pm 1.12$ $30 \mathrm{~min})$ was greater $(P<0.001)$ than the CONF snack $(0.93 \pm 0.33 \mathrm{~min})$. This study demonstrates that substituting an afternoon confectionary snack with mixed berries decreased subsequent energy intake at dinner, but did not affect subjective appetite. This dietary strategy could represent a simple method for reducing daily energy 34 intake and aiding weight management.

Keywords: Energy Balance; Appetite; Weight Management; Fruit 
38 Obesity is caused by a chronic positive energy balance; a sustained daily energy intake exceeding energy expenditure, resulting in the accumulation of adipose tissue and an increased mortality risk (James, 2004; Adams et al. 2006). With the increased prevalence of obesity worldwide (James, 2004), and its associated comorbidities (Guh et al. 2009), dietary strategies targeted at suppressing appetite and facilitating weight management are needed to support a reduced overall energy balance (Rolls, 2009).

Snack foods (snacks) are a fundamental aspect of dietary habits, contributing to greater than $18 \%$ of daily energy intake and between 1 - 4 feeding episodes per day (Ovaskainen et al. 2006; Bellisle et al. 2003). The consumption of energy dense, nutrient deficient snacks has been associated with overweight and obesity in adults (Bes-Rastrollo et al. 2010) and children (Bo et al. 2014), as well as poor metabolic health (Mirmiran et al. 2014). Decreasing the energy density of the diet, specifically snacks, by replacing energy dense foods with fruit and/ or vegetables has been proposed as a dietary strategy to decrease hunger and energy intake, and consequently promote weight loss (Ello-Martin et al. 2007; Houchins et al. 2013).

54 Evidence demonstrates that reducing the energy density of a meal (Rolls et al. 1999b; Bell et al. 1998), a snack (Farajian et al. 2010; Rolls et al. 1998), and a firstcourse entrée prior to a meal (Rolls et al. 2004; Blatt et al. 2012), can decrease meal energy intake, both independent of and when macronutrient composition is held constant.

59 Observational studies indicate that increased fruit and vegetable intake can contribute to weight maintenance (i.e. preventing weight gain) and facilitate weight loss when substituted for other energy dense foods (Boeing et al. 2012). Since snacks contribute significantly to daily energy intake, replacing energy dense snacks with fruit and/ or vegetables may promote weight loss and induce positive health benefits. Previous studies have reported that a snack of dried fruit increased satiety (Furchner-Evanson et al. 2010; Farajian et al. 2010), as well as decreased subsequent energy intake (Farajian et al. 2010) compared to other snack foods. Whilst Patel et al. (2010) reported a reduced energy intake of an ad-libitum snack of raisins (dried fruit) or grapes compared to other snacks; to the authors knowledge no 
69 research has assessed the acute appetite effects of replacing an energy dense 70 snack with fruit.

71 Given the paucity of data examining the effect of fruit intake on subsequent appetite 72 and energy intake, this topic warrants further investigation. Therefore, the purpose of 73 the present study was to compare the appetite and energy intake effects of a snack 74 of mixed berries (strawberries, raspberries, blackberries and blueberries) with an 75 isoenergetic confectionary snack (sweets). 
77 Subjects

78 Twelve pre-menopausal women (age $21 \pm 2$ y; body mass $75.6 \pm 8.9 \mathrm{~kg}$; height 1.69 $79 \pm 0.08 \mathrm{~m}$; BMl $26.6 \pm 2.6 \mathrm{~kg} \cdot \mathrm{m}^{-2}$; body fat $23 \pm 3 \%$ ) volunteered for this study, which 80 was approved by the Loughborough University Ethics Approvals (Human 81 Participants) Sub Committee (reference number: R14-P128). All subjects were healthy, non-smokers, weight stable for the past 6 months (self-reported), and not taking medications known to affect appetite. Each subject provided written informed consent, completed a medical screening questionnaire and a three-factor eating questionnaire (Stunkard \& Messick, 1985) prior to commencement of the study.

86 Subjects were not restrained, disinhibited or hunger eaters. Using previous data from 87 our laboratory (Clayton et al. 2014), an expected between trial difference of $\sim 420 \mathrm{~kJ}$, 88 between trial correlation of 0.5 , an $\alpha$ of 0.05 and a $\beta$ of 0.2 , it was estimated that 13 subjects would be required to reject the null hypothesis (Faul et al. 2009). Therefore, 15 subjects were recruited, but 3 subjects dropped out after completing the familiarisation trial (2 due to other time constraints and 1 due to becoming pregnant).

92 Each subject completed a preliminary trial and two experimental trials in a 93 randomised counterbalanced order.

Pre-trial standardisation

95 Subjects arrived for trials $4 \mathrm{~h}$ after lunch, but were able to drink water ad-libitum until 96 $2 \mathrm{~h}$ before arrival. To ensure similar metabolic conditions prior to each experimental trial, subjects recorded their dietary intake and habitual physical activity for the day of and day preceding their first experimental trial. The diet and activity patterns were replicated prior to the second experimental trial and adherence to these requirements were verbally checked. Subjects also refrained from any strenuous exercise or alcohol intake during this period. Trials were scheduled to minimise the possibility of hormone related appetite fluctuations. Three subjects were not using any form of contraceptive $(n=3)$ and their trials took place during the early-mid follicular phase of their menstrual cycle (days 5-11). Seven subjects were using a combined contraceptive pill, and their trials took place after at least 2 days continuous pill use and after day 4 of their menstrual cycle. Two subjects had a 
107 progesterone only contraceptive implant and their trials were separated by exactly 7

108 days. .

109 Preliminary trial

110 During the preliminary trial, subject's height and weight were recorded before 111 skinfold measurements were obtained from the triceps, biceps, subscapular and 112 suprailiac for the estimation of body fat percentage (Durnin \& Womersley, 1974). 113 Subjects then completed an appetite questionnaire (Flint et al. 2000) and were 114 familiarised with the ad-libitum pasta test meal.

115 Experimental trials

116 Experimental trials commenced in the late afternoon ( $5 \mathrm{pm})$, with the specific time 117 standardised for each individual subject. Upon arrival, subjects voided their bladder 118 and bowels, and body mass was recorded in light clothing (Adam Equipment Co., 119 AFW-120K, UK). Thereafter, subjects completed a subjective appetite questionnaire, 120 before being provided with a snack of either mixed berries (BERRY) or confectionary 121 (CONF). The snacks were matched for energy content, with the BERRY snack 122 consisting of $40 \mathrm{~g}$ strawberries, $40 \mathrm{~g}$ raspberries, $40 \mathrm{~g}$ blackberries and $40 \mathrm{~g}$ 123 blueberries, and the CONF snack consisting of $19.4 \mathrm{~g}$ sweets (Bassetts Jelly Babies 124 Berry Mix, Modelez UK, Birmingham, UK) (Table 1). Each snack was accompanied 125 by $100 \mathrm{ml}$ water. Subjects were instructed to consume the snack continuously as if it 126 was an afternoon snack, and the time taken for complete ingestion was recorded. All 127 trials took place in a dedicated feeding laboratory and subjects remained in complete isolation throughout, except for essential interaction with the experimenter.

129

130

131

132

133 
135 Table 1. Snack energy and macronutrient composition.

\begin{tabular}{lcc}
\hline & BERRY & CONF \\
\hline Energy $(\mathrm{kJ})$ & 272 & 272 \\
Energy density $(\mathrm{kJ} / \mathrm{g})$ & 1.7 & 14.0 \\
Protein $(\mathrm{g})$ & 1.5 & 0.7 \\
Carbohydrate $(\mathrm{g})$ & 12.1 & 15.5 \\
Fat $(\mathrm{g})$ & 0.4 & 0.0 \\
Fibre $(\mathrm{g})$ & 3.6 & 0.0 \\
Water $(\mathrm{g})$ & 142 & 3 \\
\hline
\end{tabular}

136

137 Sixty min after the start of the snack, subjects were presented with a homogenous 138 pasta test meal, which they ate ad-libitum until voluntary satiation. The test meal 139 consisted of fusilli pasta, Bolognese pasta sauce and olive oil (Tesco Stores Ltd., 140 Cheshnut, UK); each meal received identical heating and cooling. The energy 141 density of the meal was $5.87 \pm 0.03 \mathrm{~kJ} / \mathrm{g}$ and was not different between trials $142(P=0.596)$. The test meal was served to subjects in a custom built feeding booth 143 inside an isolated feeding laboratory. Subjects were initially served a large bowl of 144 pasta ( $\sim 700 \mathrm{~g})$ and a glass of water $(\sim 500 \mathrm{~g})$. After $7.5 \mathrm{~min}$, these were removed and 145 replaced with a fresh bowl of pasta $(\sim 700 \mathrm{~g})$ and glass of water $(\sim 500 \mathrm{~g})$, and 146 subjects continued eating until voluntary satiation. Before the meal, subjects 147 received standardised instructions to eat until they were "comfortably full and 148 satisfied". Subjects had $30 \mathrm{~min}$ in which to eat and remained in the feeding 149 laboratory for the entire $30 \mathrm{~min}$ period, during which time food was continuously 150 available inside the feeding booth. Subjects indicated satiation by leaving the feeding 151 booth and taking a seat in the feeding laboratory. The point at which subjects left the 152 feeding booth was recorded. All subjects left the feeding booth within the $30 \mathrm{~min}$ 153 period and did not return to the feeding booth. Food and water intake were quantified 154 by weighing bowls and glasses before and after consumption (PCB Electronic 155 Precision Scale, Kern \& Sohn $\mathrm{GmbH}$, Balingen, Germany), and energy intake was 156 determined using manufacturer values.

157 Additional appetite questionnaires were completed $15 \mathrm{~min}$ and $30 \mathrm{~min}$ after the 158 snack, immediately before and after the pasta test meal, as well as $30 \mathrm{~min}, 60 \mathrm{~min}$ 
159 and $120 \mathrm{~min}$ after the pasta test meal. Subjects left the laboratory after completing 160 the post-meal questionnaire, but were instructed not to eat, drink or perform any 161 physical activity until the final questionnaire had been completed 120 min later. For 162 each appetite questionnaire visual analogue scales were used to rate hunger "How 163 hungry do you feel?", fullness "How full do you feel?", desire to eat (DTE) "How 164 strong is your desire to eat?", prospective food consumption (PFC) "How much food 165 do you think you could eat?", and nausea "How nauseous do you feel?". Verbal 166 anchors were placed at $0 \mathrm{~mm}$ and $100 \mathrm{~mm}$ and these were "not at all" and 167 "extremely" for hunger, fullness, DTE and nausea and "none at all" and "a lot" for 168 PFC. Immediately after the snack, subjects rated the pleasantness "How pleasant 169 was the snack?", bitterness "How bitter was the snack?", and sweetness "How sweet 170 was the snack?" of the snack on $100 \mathrm{~mm}$ visual analogue scales. Again, the verbal 171 anchors "not at all" and "extremely" were placed at $0 \mathrm{~mm}$ and $100 \mathrm{~mm}$, respectively.

172 Statistical analysis

173 Data were analysed using SPSS (version 21, SPSS Inc, Chicago, IL) and were 174 initially checked for normality of distribution using a Shapiro-Wilk test. Appetite 175 sensations were analysed using two-way repeated measures ANOVA. Where the 176 assumption of sphericity was violated, the degrees of freedom were corrected using 177 the Greenhouse-Geisser estimate. Post-hoc t-tests or Wilcoxon signed rank tests 178 were used where appropriate and the family wise error rate was controlled using the 179 Holm-Bonferroni correction. Pre-trial body mass, snack ratings, as well as energy 180 intake, eating rate and water intake at the ad-libitum pasta meal were analysed using 181 t-tests or Wilcoxon signed rank tests as appropriate. Data are presented as mean \pm 182 SD unless otherwise stated. Data sets were accepted as being significantly different 183 when $P \leq 0.05$. 


\section{Results}

185 Pre-trial measures

186 There was no difference between trials for pre-trial body mass (BERRY 75.12 \pm 8.99

$187 \mathrm{~kg}$; CONF $75.09 \pm 9.19 \mathrm{~kg} ; P=0.876)$, hunger $(P=0.477)$, fullness $(P=0.136)$, DTE $188(P=0.922)$, PFC $(P=0.319)$ or nausea $(P=0.463)$.

189 Ad-libitum meal

190 Energy intake at the ad-libitum meal was greater during CONF than BERRY 191 (BERRY $2890 \pm 611 \mathrm{~kJ}$; CONF $3449 \pm 719 \mathrm{~kJ} ; P<0.001$ ), with a mean increase of $19219.5 \pm 9.7 \%$ during CONF (range $8.3-34.7 \%$; Figure 1). Water consumed with the 193 meal was not different between trials (BERRY $362 \pm 122 \mathrm{~g}$; CONF $365 \pm 179 \mathrm{~g}$; $194 P=0.925$ ), although there was a tendency for total water consumption (from both food 195 and drink) to be greater during CONF (BERRY $692 \pm 128 \mathrm{~g}$; CONF $765 \pm 153 \mathrm{~g}$; $196 P=0.077)$. All subjects terminated eating within the $30 \mathrm{~min}$ feeding period and there 197 was no difference between trials for time spent eating (BERRY 10.21 $\pm 1.76 \mathrm{~min}$; 198 CONF $11.06 \pm 2.33 \mathrm{~min} ; P=0.119)$. There was a trend for eating rate during the ad199 libitum test meal to be greater during CONF (BERRY $286 \pm 60 \mathrm{~kJ} / \mathrm{min}$; CONF $333 \pm$ $200133 \mathrm{~kJ} / \mathrm{min})$, although this did not reach significance $(P=0.081)$.

201

202

203

204

205

206

207

208

209

210 
a)

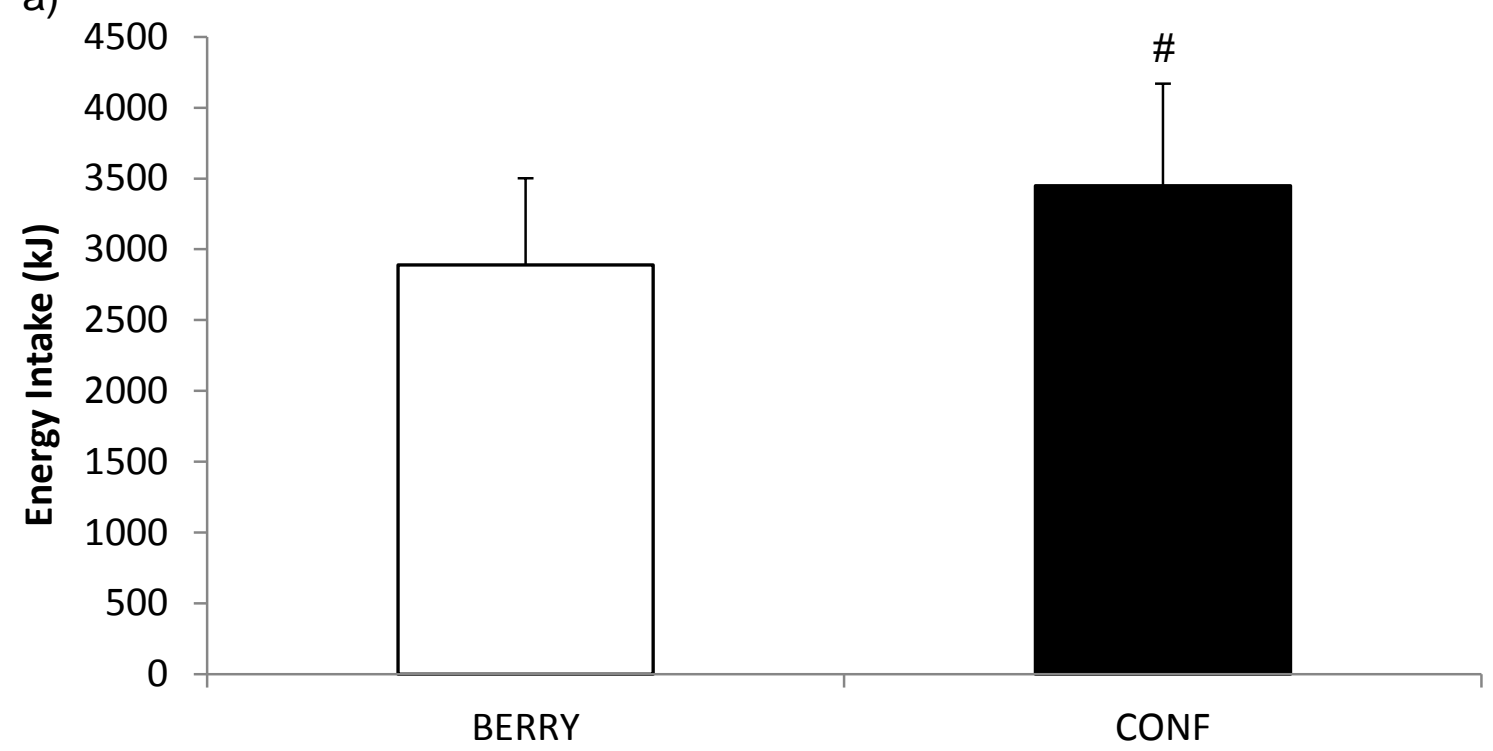

211

b)

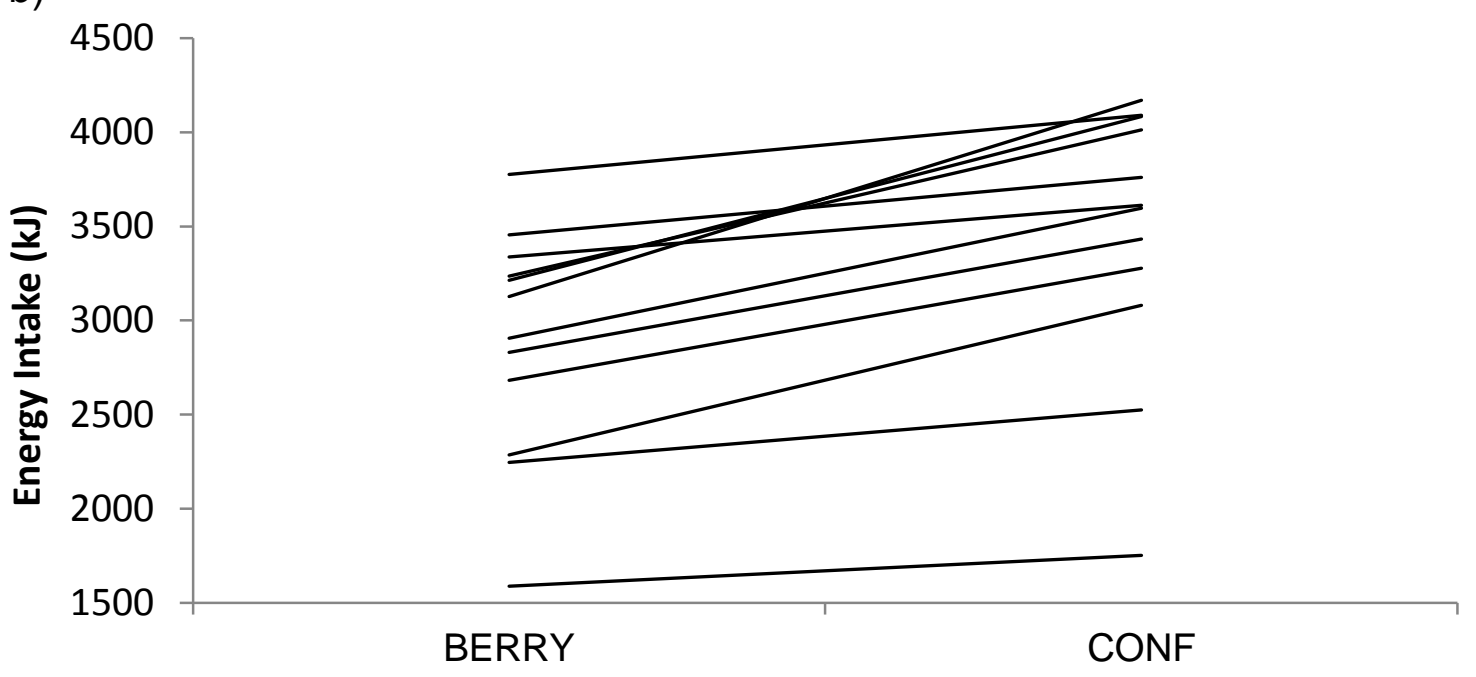

213 Figure 1. Mean (a) and individual (b) energy intakes (kJ) at the ad-libitum meal after 214 consumption of BERRY and CONF. \# Indicates significantly different from BERRY. 215 Data are mean \pm SD.

216

217

218

219

220 
221 Subjective appetite ratings

222 There were main effects of time for all subjective appetite ratings $(P<0.001)$. There 223 were no main effects of trial (hunger $P=0.162$; fullness $P=0.730$; DTE $P=0.088$; PFC $224 P=0.095$ ) or interaction effects (hunger $P=0.499$; fullness $P=0.483$; DTE $P=0.540$; 225 PFC $P=0.351$ ) for any of the subjective appetite ratings (Figure 2). There was also 226 no time $(P=0.566)$, trial $(P=0.987)$ or interaction $(P=0.474)$ effect for nausea (data not 227 shown).

228

229

230

231

232

233

234

235

236

237

238

239

240

241

242

243

244 


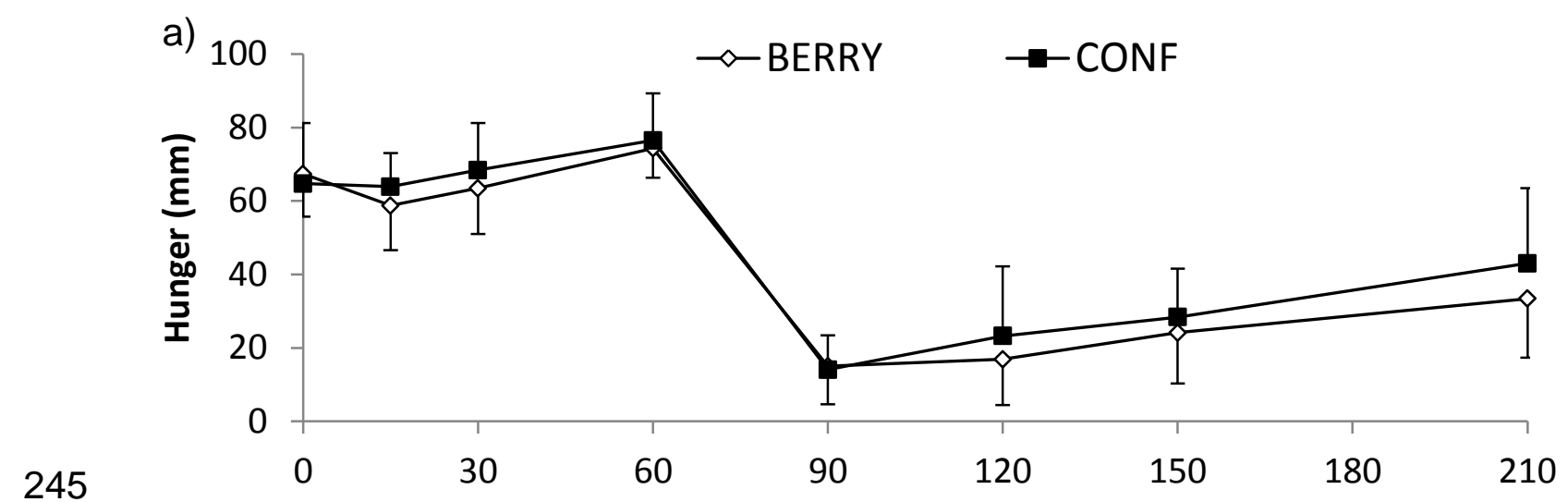

246

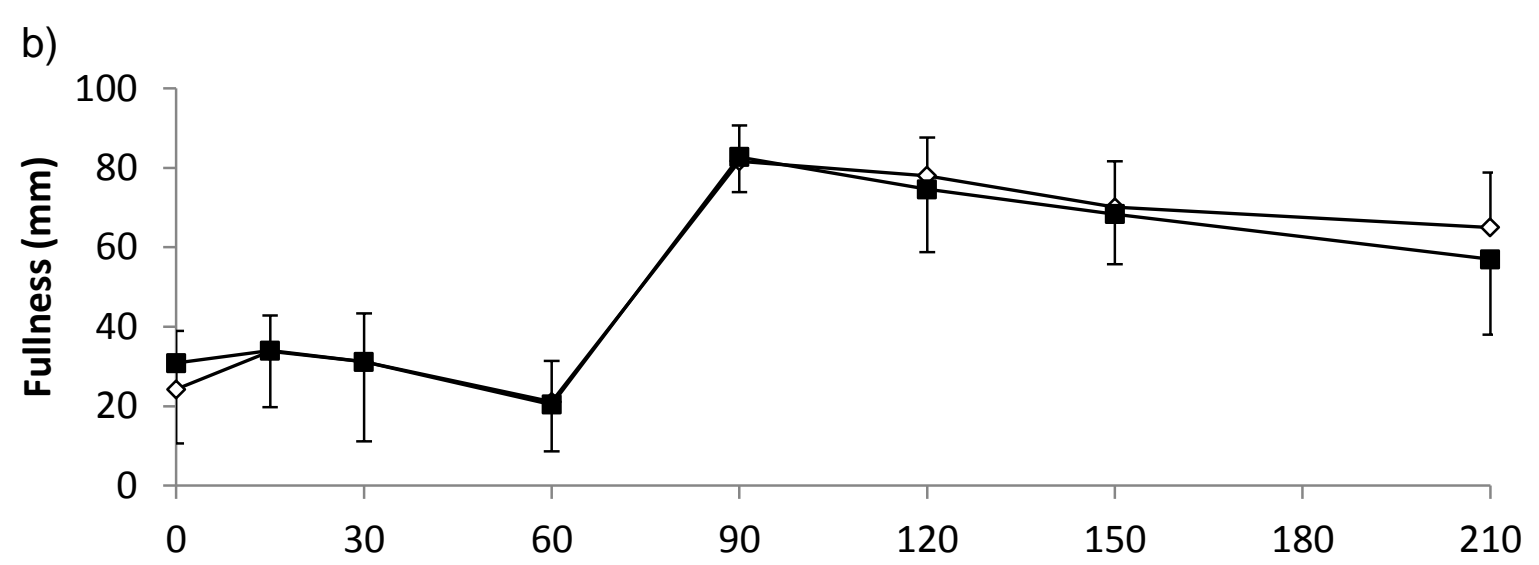

247
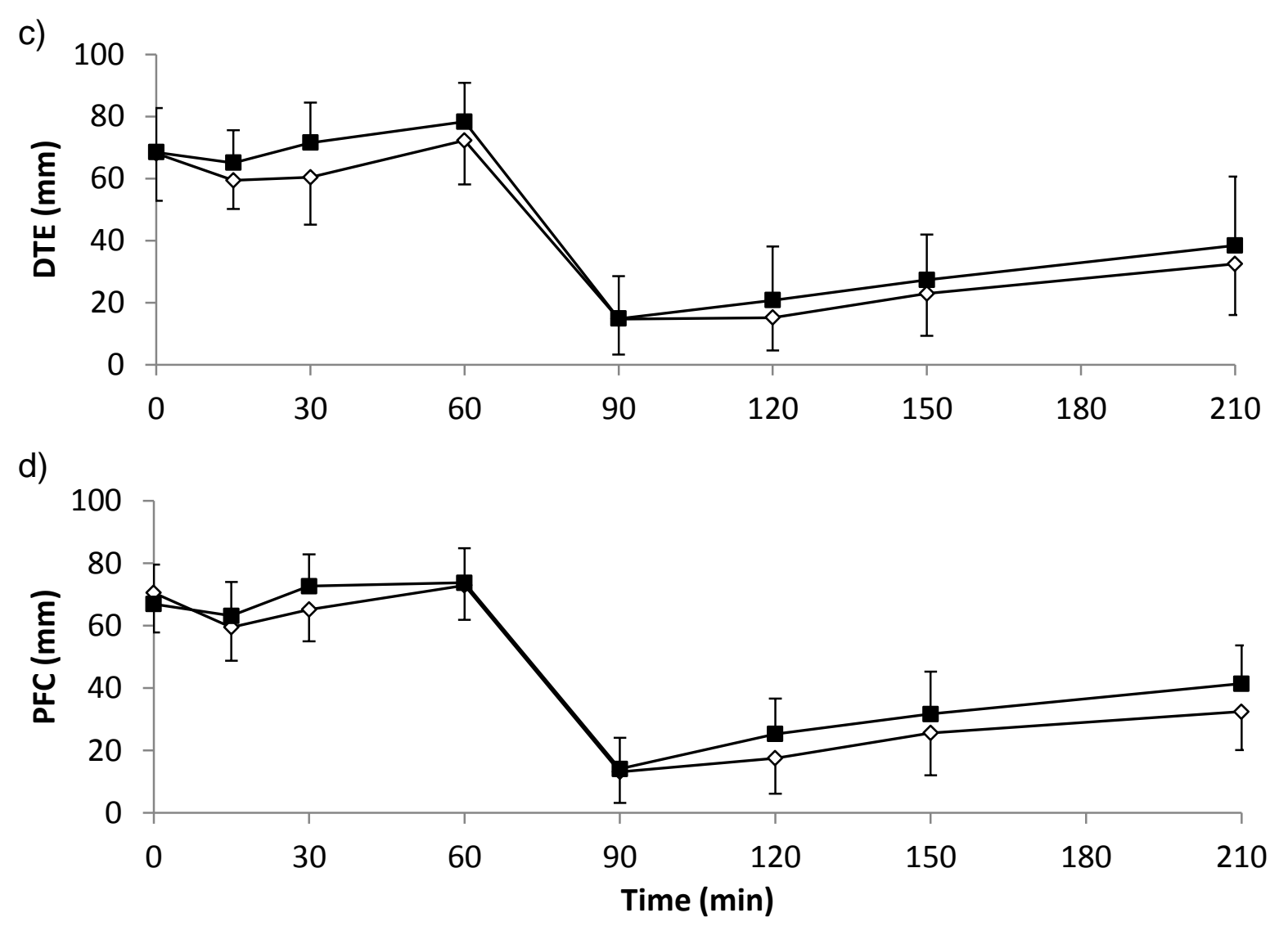

248

249 Figure 2. Subjective feelings of a) hunger, b) fullness, c) desire to eat (DTE) and d) 250 prospective food consumption (PFC). Data are mean \pm SD. 
251 Snacks

252 The BERRY snack took longer to consume than the CONF snack $(4.05 \pm 1.12 \mathrm{~min}$ 253 vs. $0.93 \pm 0.33 \mathrm{~min} ; P<0.001)$. The BERRY snack was rated as more pleasant and 254 more bitter, as well as less sweet than the CONF snack $(P<0.001$; Figure 3$)$.

255

256

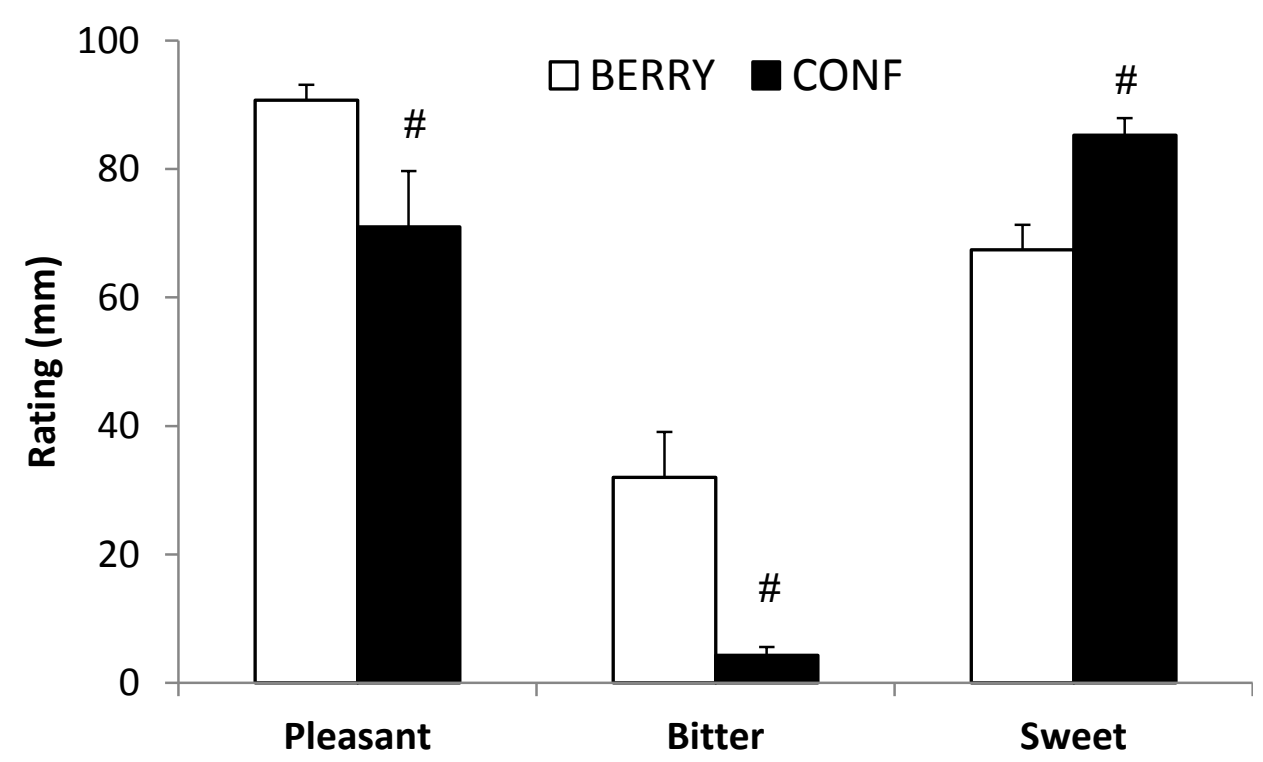

258 Figure 3. Subjective ratings of the snacks. \# Indicates significantly different from 259 BERRY. Data are mean \pm SD. 


\section{Discussion}

261 The aim of the present study was to compare the appetite and subsequent energy 262 intake effects of a snack of mixed berries with an isoenergetic confectionary snack. 263 The main finding was that energy intake at an ad-libitum test meal provided $1 \mathrm{~h}$ after 264 the snack was $\sim 20 \%$ greater after consumption of the confectionary snack than after 265 the mixed berries snack.

266 To our knowledge, this is the first study to compare the acute effects of a fruit 267 (specifically berries) snack to an energy dense confectionary snack food on 268 subsequent appetite and energy intake. Previous investigations have assessed the 269 effect of dried fruit on subsequent appetite and energy intake (Farajian et al. 2010; 270 Furchner-Evanson et al. 2010) or with-in snack energy intake (Patel et al. 2013). 271 Furchner-Evanson et al. (2010) reported that compared to low-fat cookies, an 272 isoenergetic snack of dried plums increased satiety after ingestion, but had no effect 273 on ad-libitum energy intake at a meal $2 \mathrm{~h}$ later. In a similar experiment, Farajian et al. 274 (2010) reported increased satiety after a snack of dried prunes compared to an 275 isoenergetic amount of bread, as well a reduction in ad-libitum food intake at a meal $2763 \mathrm{~h}$ after the snack. In a different study design Patel et al. (2013) reported that when 277 allowed to consume a snack ad-libitum children (4-11 years) consumed less energy 278 when provided with an after school snack of raisins or grapes (i.e. dry and fresh fruit) 279 than when they were provided potato chips or cookies. Taken together with the 280 results of the present study, these studies suggest that substituting other snack foods with fruit may reduce acute energy intake from the snack or at the next eating opportunity.

283 Whilst the scope of the present investigation does not allow the mechanisms responsible for the observed finding to be elucidated, there are a number of potential explanations for these findings. The difference in energy density of the snack (Rolls et al. 1998), eating rate of the snacks (Zhu and Hollis, 2014) or expected satiety related to the snacks (Brunstrom, 2014) might all have contributed to the observed effects.

289 Since the two snacks were matched for energy content and similar in macronutrient 290 composition, the decrease in subsequent energy intake following the mixed berries 291 snack could have been due to the considerably lower energy density (BERRY 1.7 
$292 \mathrm{~kJ} / \mathrm{g}$; CONF $14 \mathrm{~kJ} / \mathrm{g}$ ) and larger volume (BERRY $160 \mathrm{~g}$; CONF $19.4 \mathrm{~g}$ ). Rolls et al. 293 (1998) assessed the effect of decreasing the energy density and increasing the 294 volume of milk, from $300 \mathrm{ml}$ to $450 \mathrm{ml}$ and $600 \mathrm{ml}$, while maintaining the energy 295 content and macronutrient composition. Decreasing the energy density suppressed 296 hunger and increased fullness, as well as reduced energy intake at an ad-libitum 297 lunch 30 min after consumption of the milk. In a separate study, Rolls et al. (1999a) 298 found that decreasing the energy density and increasing the volume of chicken 299 casserole, by adding $356 \mathrm{~g}$ of water to produce chicken casserole soup, enhanced 300 satiety and decreased energy intake at an ad-libitum lunch 5 min later. The volume 301 of water and food in the abovementioned studies far exceed the water present in the 302 mixed berries snack (142 g), and therefore, it seems less likely that the lower energy 303 density and larger volume of the mixed berries snack were responsible for the 304 decrease in energy intake at the ad-libitum meal. The mechanisms relating to a 305 reduced energy density and increase in volume on subsequent decreases in energy 306 intake are unknown. However, cognitive factors, such as expected satiety 307 (Brunstrom, 2014), and sensory factors, such as oral processing time, 308 mechanoreceptors and chemoreceptors in the oropharyngeal and gastro-intestinal 309 tracts (Read et al. 1994), have been proposed.

310 Recent literature indicates that slowing ingestion rate, and subsequently increasing 311 meal duration, can reduce energy intake (Andrade et al. 2008) and increase 312 postprandial satiety (Kokkinos et al. 2010; Zandian et al. 2009; Azrin et al. 2008). 313 Moreover, manipulating oral processing time, through an increase in the number of 314 chewing cycles, has been shown to reduce food intake, by $9.5 \%$ and $14.8 \%$, when 315 the number of chews was increased to $150 \%$ and $200 \%$ from baseline, respectively 316 (Zhu \& Hollis, 2014). The aforementioned studies manipulated within-meal oral 317 processing time, but the present study suggests that the oral processing time of the 318 snacks might have impacted on eating rate during the test meal, which possibly 319 affected ad-libitum energy intake. There was a trend $(P=0.081)$ for eating rate to be 320 slower during the ad-libitum meal following the mixed berries snack (286 $\pm 60 \mathrm{~kJ} / \mathrm{min})$ 321 compared to the confectionary snack (333 $\pm 133 \mathrm{~kJ} / \mathrm{min})$, which could have 322 contributed to the decrease in energy intake and warrants further investigation.

323 In contrast to two previous studies (Furchner-Evanson et al. 2010; Farajian et al. 324 2010), we did not observe any differences in post-ingestive appetite between the 
snacks. Furchner-Evanson et al. (2010) reported that post-ingestive satiety was greater after a snack of dried plums compared to low-fat cookies and white bread.

327 Subjects also reported a decreased desire to eat during the dried plum trial compared to the low-fat cookie trial. Similarly, Farajian et al. (2010) found a reduction in hunger, desire to eat, and motivation to eat, as well as increased satiety, after a snack of dried prunes compared to an isoenergetic bread snack. The dissimilar findings between previous studies (Furchner-Evanson et al. 2010; Farajian et al. 2010) and the present study could be due to the lower energy content of the snacks provided in the present study (272 kJ vs. $\sim 1000 \mathrm{~kJ})$. Despite the lower energy content, the volume (160 g) and energy (272 kJ) of the mixed berries consumed in the present study would be considered as a tangible snack, providing greater ecological validity to the present study results. Additionally, as snacks tend not to eaten to satiety (Brunstrom et al. 2008), their expected satiety and consequent effects on subjective appetite ratings may be under-estimated.

339 Other studies indicate that foods high in fibre content can promote satiety (French \& 340 Read, 1994) and decrease energy intake during subsequent eating opportunities 341 (Burley et al. 1993). Proposed mechanisms include increased mastication, 342 decreased food energy density, promotion of gastric distention, and decreased rate 343 of gastric emptying and nutrient absorption resulting in lower postprandial glucose 344 levels and insulin secretion (Howarth et al. 2001). There has been some suggestion 345 that the fibre content of a snack might impact upon subsequent energy intake 346 (Farajian et al. 2010). However, Flood-Obbagy and Rolls (2009) found no difference 347 in ad-libitum energy intake $15 \mathrm{~min}$ after consuming isoenergetic applesauce 348 (containing fibre), apple juice without fibre and apple juice with re-introduced fibre. 349 The applesauce and apple juice with re-introduced fibre contained more fibre (4.8 g) 350 than the berries in the present study $(3.6 \mathrm{~g})$ and the dried prunes $(3.6 \mathrm{~g})$ in Farajian 351 et al. (2010). This indicates that the fibre present in the mixed berries snack in this study was unlikely to influence satiety or subsequent energy intake.

353 In contrast to within-meal events, it has been proposed that prior to consuming a $354 \mathrm{food} / \mathrm{meal}$, an 'expected satiety' (expectation of a foods effect on fullness) is estimated from previous experience and memory of recent consumption (Brunstrom, 2014). This 'expected satiety' may largely dictate consequent meal size, and 357 perceived hunger and fullness (Brunstrom, 2014; Brunstrom et al. 2008). In order to 
energy match the conditions in the present study; $19.4 \mathrm{~g}$ of the confectionary snack were consumed, compared to $160 \mathrm{~g}$ of mixed berries. Due to the considerably lower volume of sweets used, the 'expected satiety' of the confectionary snack may have been lower than the mixed berries snack. Therefore, a lower 'expected satiety' could have led to an increased energy intake during the ad-libitum meal, or on the contrary, a higher 'expected satiety' of the mixed berries snack, to a lower meal energy intake. This is re-enforced by Flood-Obbagy and Rolls (2010) who found a decrease in energy intake after consuming apple segments compared to isoenergetic apple juice and applesauce. Prior to consumption, the apple segments were perceived as being more satiating than the isoenergetic serving of apple juice. For future studies it may be beneficial to quantify subjects' satiety expectations to the specific foods used in the study (Brunstrom et al. 2008).

Whilst in an acute setting replacing a confectionary snack with mixed berries might reduce subsequent energy intake, whether this results in a chronic reduction in energy intake is beyond the scope of this investigation. Future investigations should seek to examine the effect of such a dietary intervention on weight management, as well as a number of other outcomes, such as acute dietary compensation and energy expenditure. With the exception of one subject, all the subjects in this experiment were female university students aged 18-25 and thus the homogeneity of the population group likely explains the consistencyof the data. Although a greater number of similar subjects would be unlikely to alter the results, future studies should seek to examine the influence of similar snacking interventions in a larger more heterogeneous population.

In conclusion, the present study demonstrates that, although no differences for 382 subjective appetite were present after a snack of mixed berries compared to an 383 isoenergetic confectionary snack, ad-libitum energy intake at a pasta meal $1 \mathrm{~h}$ later was reduced by $19.5 \pm 9.7 \%$ after the mixed berries snack. Replacing an energy dense confectionary snack with a snack of mixed berries might represent a useful strategy to reduce subsequent energy intake and facilitate weight management. 387 Future studies should seek to examine the effect of chronically replacing confectionary snacks with fruit and/ or vegetables to determine the effects on body mass and composition during a chronic intervention. 


\section{Acknowledgements}

391 Financial support for the conduct of the research was provided by British Summer 392 Fruits (British Summer Fruits, London, UK), however, the funding source had no 393 involvement in the study design, the collection, analysis and interpretation of data, 394 and writing of the report. The funding source has seen the final manuscript prior to 395 submission, but did not contribute in the decision to submit the article for publication. 


\section{References}

398 Adams K, Schatzkin A, Harris T, Kipnis V, Mouw T, Ballard-Barbash R, Hollenback A 399 and Leitzmann M (2006) Overweight, obesity, and mortality in a large prospective 400 cohort of persons 50 to 71 years old. The New England Journal of Medicine, 355, 401 763-778.

402 Andrade A, Greene G and Melanson K (2008) Eating slowly led to decreases in 403 energy intake within meals in healthy women. Journal of the American Dietetic 404 Association, 108 (7), 1186-1191.

405 Azrin N, Kellen M, Brooks J, Ehle C and Vinas V (2008) Relationship between rate of 406 eating and degree of satiation. Child \& Family Behavior Therapy, 30 (4), 355-364.

407 Bell E, Castellanos V, Pelkman C, Thorwart M and Rolls B (1998) Energy density of 408 foods affects energy intake in normal-weight women. The American Journal of 409 Clinical Nutrition, 67, 412-420.

410 Bellisle F, Dalix A, Mennen L, Galan P, Hercberg S, de Castro J and Gausseres N 411 (2003) Contribution of snacks and meals in the diet of French adults: a diet-diary 412 study. Physiology \& Behaviour, 79, 183-189.

413 Bes-Rastrollo M, Sanchez-Villegas A, Basterra-Gortari F, Nunez-Corboda J, Toledo 414 E and Serrano-Martinez M (2010) Prospective study of self-reported usual snacking 415 and weight gain in a Mediterranean cohort: the SUN project. Clinical Nutrition, 29 (3), $416 \quad 323-330$.

417 Blatt A, Williams R, Roe L and Rolls B (2012) Effects of energy content and energy 418 density of pre-portioned entrées on energy intake. Obesity, 20 (10), 2010-2018.

419 Bo S, De Carli L, Venco E, Fanzola I, Maiandi M, De Michieli F, Durazzo M, Beccuti 420 G, Cavallo-Perin P, Ghigo E and Ganzit G (2014) Impact of snacking pattern on 421 overweight and obesity risk in a cohort of 11- to 13-year-old adolescents. Journal of 422 Pediatric Gastroenterology and Nutrition, 59 (4), 465-471.

423 Boeing $\mathrm{H}$, Bechthold A, Bub A, Ellinger S, Haller D, Kroke A, Leschik-Bonnet E, 424 Müller $M$, Oberritter $H$, Schulze $M$, Stehle $P$ and Watzl B (2012) Critical review: 
425 vegetables and fruit in the prevention of chronic diseases. European Journal of 426 Nutrition, 51, 637-663.

427 Brunstrom J (2014) Mind over platter: pre-meal planning and the control of meal size 428 in humans. International Journal of Obesity, 38, 9-12.

429 Brunstrom J, Shakeshaft N and Scott-Samuel N (2008) Measuring 'expected satiety' 430 in a range of common foods using a method of constant stimuli. Appetite, 51, 604431614.

432 Burley V, Paul A and Blundell J (1993) Sustained post-ingestive action of dietary 433 fibre: effects of a sugar-beet-fibre-supplemented breakfast on satiety. Journal of 434 Human Nutrition and Dietetics, 6 (3), 253-260.

435 Clayton D, Stensel D, Watson $P$ and James $L$ (2014) The effect of post-exercise 436 drink macronutrient content on appetite and energy intake. Appetite, 82, 173-179.

437 Durnin J and Womersley J (1974) Body fat assessed from total body density and its 438 estimation from skinfold thickness: measurements on 481 men and women aged 439 from 16 to 72 years. British Journal of Nutrition, 32 (1), 77-97.

440 Ello-Martin J, Roe L, Ledikwe J, Beach A and Rolls B (2007) Dietary energy density 441 in the treatment of obesity: a year-long trial comparing 2 weight-loss diets. The 442 American Journal of Clinical Nutrition, 85 (6), 1465-1477.

443 Farajian P, Katsagani M and Zampelas A (2010) Short-term effects of a snack 444 including dried prunes on energy intake and satiety in normal-weight individuals. 445 Eating Behaviours, 11, 201-203.

446 Faul F, Erdfelder E, Buchner A and Albert-Georg L (2009) Statistical power analyses 447 using $G^{*}$ Power 3.1: Tests for correlation and regression analyses. Behavior 448 Research Methods, 41, 1149-1160.

449 Flint A, Raben A, Blundell J and Astrup A (2000) Reproducibility, power and validity 450 of visual analogue scales in assessment of appetite sensations in single test meal 451 studies. International Journal of Obesity, 24, 38-48.

452 Flood-Obbagy $\mathrm{J}$ and Rolls B (2009) The effect of fruit in different forms on energy 453 intake and satiety at a meal. Appetite, 52 (2), 416-422. 
454 French S and Read N (1994) Effect of guar gum on hunger and satiety after meals of 455 differing fat content: relationship with gastric emptying. The American Journal of 456 Clinical Nutrition, 59, 87-91.

457 Furchner-Evanson A, Petrisko Y, Howarth L, Nemoseck T and Kern M (2010) Type 458 of snack influences satiety responses in adult women. Appetite, 54, 564-569.

459 Guh D, Zhang W, Bansback N, Amarsi Z, Laird Birmingham C and Anis A (2009) 460 The incidence of co-morbidities related to obesity and overweight: a systematic 461 review and meta-analysis. BMC Public Health, 9, 88-108.

462 Houchins J, Tan S, Campbell W and Mattes R (2013) Effects of fruit and vegetable, 463 consumed in solid vs. beverage forms on acute and chronic appetite responses in 464 lean and obese adults. International Journal of Obesity, 37 (8), 1109-1115.

465 Howarth N, Saltzman E and Roberts S (2001) Dietary fiber and weight regulation. 466 Nutrition Reviews, 59 (5), 129-139.

467 James P (2004) Obesity: the worldwide epidemic. Clinics in Dermatology, 22 (4), 468 276-280.

469 Kokkinos A, le Roux C, Alexiadou K, Tentolouris N, Vincent R, Kyriaki D, Perrea D, 470 Ghatei M, Bloom S and Katsilambros N (2010) Eating slowly increases the 471 postprandial response of the anorexigenic gut hormones, peptide $Y Y$ and glucagon472 like peptide-1. The Journal of Clinical Endocrinology \& Metabolism, 95 (1), 333-337.

473 Mirmiran P, Bahadoran Z, Delshad H and Azizi F (2014) Effects of energy-dense 474 nutrient-poor snacks on the incidence of metabolic syndrome: a prospective 475 approach in Tehran Lipid and Glucose Study. Nutrition, 30 (5), 538-543.

476 Ovaskainen M, Reinivuo H, Tapanainen H, Hannila M, Korhonen T and Pakkala H 477 (2006) Snacks as an element of energy intake and food consumption. European 478 Journal of Clinical Nutrition, 60, 494-501.

479 Patel B, Bellissimo N, Luhovyy B, Bennett L, Hurton E, Painter J and Anderson G 480 (2013) An after-school snack of raisins lowers cumulative food intake in young 481 children. Journal of Food Science, 71 (1), 5-10. 
482 Read N, French S and Cunningham K (1994) The role of the gut in regulating food 483 intake in man. Nutrition Reviews, 52 (1), 1-10.

484 Rolls B (2009) The relationship between dietary energy density and energy intake. 485 Physiology \& Behaviour, 97 (5), 609-615.

486 Rolls B, Bell E and Thorwart M (1999a) Water incorporated into a food but not 487 served with a food decreases energy intake in lean women. The American Journal of 488 Clinical Nutrition, 70, 448-455.

489 Rolls B, Bell E, Castellanos V, Chow M, Pelkman C and Thorwart M (1999b) Energy 490 density but not fat content of foods affected energy intake in lean and obese women. 491 The American Journal of Clinical Nutrition, 69, 863-871.

492 Rolls B, Castellanos V, Halford J, Kilara A, Panyam D, Pelkman C, Smith G and 493 Thorwart M (1998) Volume of food consumed affects satiety in men. The American 494 Journal of Clinical Nutrition, 67 (6), 1170-1177.

495 Rolls B, Roe L and Meengs J (2004) Salad and satiety: energy density and portion 496 size of a first-course salad affect energy intake at lunch. Journal of the American 497 Dietetic Association, 104 (10), 1570-1576.

498 Stunkard A and Messick S (1985) The three-factor eating questionnaire to measure 499 dietary restraint, disinhibition and hunger. Journal of Psychosomatic Research, 29 500 (1), 71-83.

501 Zandian M, loakimidis I, Bergh C, Brodin U and Södersten P (2009) Decelerated and 502 linear eaters: effect of eating rate on food intake and satiety. Physiology \& Behaviour, $50396(2), 270-275$.

504 Zhu $\mathrm{Y}$ and Hollis $\mathrm{J}$ (2014) Chewing thoroughly reduces eating rate and postprandial 505 food palatability but does not influence meal size in older adults. Physiology \& 506 Behaviour, 123, 62-66. 